\title{
Changes in the incidence of acute appendicitis in Glasgow Asian and white children between 1971 and 1985
}

\author{
L M MATHESON, ${ }^{1}$ J B HENDERSON, ${ }^{2}$ D HOLE, ${ }^{3}$ AND M G DUNNIGAN ${ }^{2}$ \\ From the Medical Division, Stobhill General Hospital, ${ }^{2}$ Glasgow G21; West of Scotland Cancer Surveillance Unit, ${ }^{3}$ \\ Ruchill Hospital, Glasgow G20; and the Department of Radiotherapy and Oncology, Western General Hospital, ${ }^{1}$ \\ Edinburgh EH4.
}

SUMMARY Between 1971 and 1985 there was a significant rise in the annual hospital discharge rate for acute appendicitis in Glasgow Asian* boys aged 10-19.9 years. A smaller and statistically insignificant rise occurred in Asian girls of 10-19.9 years; discharge rates for younger Asian boys and girls did not change significantly. In keeping with national trends, discharge rates for acute appendicitis in all Glasgow children fell significantly between 1971-85. The divergent trend in older Asian children may reflect dietary adaptation which is most marked in older Asian boys.

Appendicitis became common in industrialised countries at the end of the 19 th century. ${ }^{1}$ Burkitt $^{2}$ and others have suggested that this was due to the reduced consumption of dietary fibre associated with the introduction of refined flour to national diets. Most British Asians consume a diet which is considerably lower in meat and meat products and higher in dietary fibre than the indigenous population but many Asian children are adopting more western dietary patterns. The availability of appropriate population denominators has allowed a comparison of underlying trends in hospital discharge rates for acute appendicitis with appendicectomy in Glasgow Asian and white children between 1971 and 1985 inclusive.

\section{Materials and methods}

Details of patients discharged from Greater Glasgow Health Board (GGHB) hospitals with a diagnosis of acute appendicitis (ICD 540, 541) with appendicectomy (OPCS 441, 444) were obtained from the Information Services Departments of the Scottish Home and Health Department and the Greater Glasgow Health Board for the years 1971-85 inclusive. The number of discharges of white and Asian children aged $0-9.9$ and $10-19.9$ years inclusive

*In the present communication the word Asian implies an ethnic origin in the Indian sub-continent (India, Pakistan or Sri Lanka). per thousand children at risk was calculated for each year. Asian children were identified by names suggesting an ethnic origin in India, Pakistan, Bangladesh or Sri Lanka with the help of an Asian co-worker. This method has been shown to identify Asian patients accurately. ${ }^{3}$

The annual size of the total GGHB population denominators in the 0-9.9 and 10-19.9 year age groups was estimated from the Office of Population Censuses and Surveys (OPCS) based on the $1971^{4}$ and $1981^{5}$ censuses; population estimates were also available for each inter-censal year. The non-white population of Glasgow born in the New Commonwealth and Pakistan is small, comprising an estimated $3.6 \%$ of the population. ${ }^{5}$ The total population of the GGHB area aged 0-19.9 years was therefore assumed to consist almost entirely of white children and adolescents.

The number of Asian children in Britain is not recorded in any national data source. Glasgow District Education Department is unusual in compiling an annual register of schoolchildren of non-British origin which lists the ethnic origin of the child's parents. The estimated annual size of Asian population denominators for Glasgow District was derived from this register. The number of Asian children in each year of full-time primary and secondary education in the city (assumed to be 5-16.9 years) was first calculated. The number of Glasgow 
Asian children aged $0-4.9$ years in each of the years 1971-85 was then estimated from the number in the first year of primary education for five years after the year of study. For years in which numbers were unavailable (one in 1981, increasing to five in 1985), the number in the first year of primary education nearest the missing year or years was employed. Similarly, the number of Asian adolescents aged 16-19.9 years in each year was estimated from the number in the fourth year of secondary education for four years before the year of study. For years in which numbers were unavailable (one in 1975, increasing to five in 1971), the number in the fourth year of secondary education nearest the missing year or years was employed.

The GGHB catchment area includes suburbs which are outside the catchment area of Glasgow District Education Authority. Postal districts to which patients were discharged from hospital were available for the years 1974-85 inclusive. For these years, annual discharge rates were estimated by using the number of Asian children discharged to postal districts within Glasgow District as the numerator and the estimated number of Asian children derived from the Education Department's register as the denominator. Before 1974, information on hospital discharges was not available on a post-code basis. For the years 1971-73 inclusive, the Asian numerator may be slightly inflated. The size of this bias can be indirectly estimated; 13 of 102 Asian children (13\%) were discharged to addresses outside Glasgow District but within the GGHB catchment area between 1974 and 1985. It seems acceptable to include all discharges for 1971-73 since any introduced bias would run counter to the direction of the trend being investigated.

\section{STATISTICAL METHODS}

The underlying trends in annual discharge rates for appendicectomy for acute appendicitis between 1971 and 1985 were estimated by linear regression analysis (this form of the analysis provided the best goodness of fit). The significance of the trends was assessed by calculating the significance of the regression coefficients which provide the probability values quoted in table 3 (Results, below). In a further regression analysis, comparison of the significance of the differences in trends between comparable Asian and white groups and between Asian boys and girls was made by using the differences in hospital discharge rates for each year as the dependent variable in the analysis (table 4).

\section{Results}

Between 1971 and 1985 inclusive, 128 Glasgow Asian children aged 0-19.9 years had appendicectomies for acute appendicitis. The mean discharge rate for appendicectomy for Asian boys aged 10-19.9 years was three times greater in the last seven years of the survey (1979-85) than in the first eight years (1971-78; table 1). The mean discharge rate for Asian girls aged $10-19.9$ years showed a smaller rise of $32 \%$ between the last seven and first eight years of the survey. Mean discharge rates for Asian boys and girls aged 0-9.9 years did not rise between 1971 and 1985 .

Table 1 Annual discharges of Asian children and adolescents with a diagnosis of acute appendicitis with appendicectomy from (a) all Greater Glasgow Health Board hospitals (197173) and (b) all Greater Glasgow Health Board hospitals to postal addresses in Glasgow District only (1974-85)

\begin{tabular}{|c|c|c|c|c|c|c|c|c|}
\hline \multirow[b]{3}{*}{ Year } & \multicolumn{8}{|c|}{ Age group } \\
\hline & \multicolumn{4}{|c|}{$0-9.9$ years } & \multicolumn{4}{|c|}{$10-19.9$ years } \\
\hline & $\begin{array}{l}\text { Boys } \\
\text { No }\end{array}$ & Rate* & $\begin{array}{l}\text { Girls } \\
\text { No }\end{array}$ & Rate $^{*}$ & $\begin{array}{l}\text { Boys } \\
\text { No }\end{array}$ & Rate* & $\begin{array}{l}\text { Girls } \\
\text { No }\end{array}$ & Rate \\
\hline 1971 & 2 & 1.5 & 3 & $2 \cdot 3$ & 1 & $1 \cdot 2$ & 1 & $1 \cdot 1$ \\
\hline 1972 & 0 & 0 & 0 & 0 & 1 & $1 \cdot 1$ & 2 & $2 \cdot 5$ \\
\hline 1973 & 1 & 0.7 & 0 & 0 & 1 & $1 \cdot 1$ & 5 & 5.9 \\
\hline 1974 & 2 & 1.4 & 3 & 1.9 & 3 & 3.5 & 2 & $2 \cdot 4$ \\
\hline 1975 & 0 & 0 & 1 & 0.7 & 0 & 0 & 1 & $1 \cdot 1$ \\
\hline 1976 & 1 & 0.7 & 0 & 0 & 2 & $2 \cdot 1$ & 0 & 0 \\
\hline 1977 & 5 & $3 \cdot 1$ & 2 & $1 \cdot 2$ & 1 & 1.0 & 1 & $1 \cdot 0$ \\
\hline 1978 & 2 & $1 \cdot 2$ & 2 & $1 \cdot 3$ & 4 & $4 \cdot 2$ & 1 & 1.0 \\
\hline 1979 & $\overline{1}$ & 0.6 & $\overline{1}$ & 0.6 & 3 & $2 \cdot 7$ & 1 & 0.9 \\
\hline 1980 & 1 & 0.6 & 2 & $1 \cdot 2$ & 11 & 9.9 & 4 & 3.6 \\
\hline 1981 & 3 & 1.9 & 0 & 0 & 6 & 5.4 & 4 & 3.5 \\
\hline 1982 & 2 & $1 \cdot 2$ & 2 & $1 \cdot 2$ & 2 & 1.7 & 2 & $1 \cdot 7$ \\
\hline 1983 & 1 & 0.6 & 0 & 0 & 6 & 4.9 & 2 & 1.7 \\
\hline 1984 & $i$ & 0.6 & 1 & 0.6 & 5 & $4 \cdot 1$ & 5 & $4 \cdot 1$ \\
\hline 1985 & 0 & 0 & 1 & 0.5 & 8 & 6.0 & 3 & $2 \cdot 3$ \\
\hline $1971-78$ & 13 & $1 \cdot 1$ & 11 & 0.9 & 13 & 1.8 & 13 & 1.9 \\
\hline $1979-85$ & 9 & 0.8 & 7 & 0.6 & 41 & $5 \cdot 0$ & 21 & $2 \cdot 5$ \\
\hline
\end{tabular}

*Annual discharge rate per 1000 Asian children in Glasgow District.

Linear regression analysis showed a significant rise in the annual discharge rate for appendicectomy for acute appendicitis in Asian boys aged 10-19.9 years between 1971 and 1985 (table 3; figure). There were no significant trends in discharge rates for younger Asian boys aged 0-9.9 years or for Asian girls. There were significant falls in annual discharge rates for appendicectomy for acute appendicitis in white children in all four age groups over this period (tables 2 \& 3; figure).

Between 1971 and 1985, trends in discharge rates between Asian and white boys aged 10-19.9 years were significantly different; the difference in discharge rates between Asian and white girls in this age group approached statistical significance over this period (table 4). Trends in discharge rates between younger Asian and white children aged 0-9.9 years did not differ significantly. There was a significant difference 
Table 2 Annual discharges of all ("white") children and adolescents aged 0-19.9 years with a diagnosis of acute appendicitis with appendicectomy from all Greater Glasgow Health Board (GGHB) hospitals between 1971 and 1985

\begin{tabular}{|c|c|c|c|c|c|c|c|c|}
\hline \multirow[b]{3}{*}{ Year } & \multicolumn{8}{|c|}{ Age group } \\
\hline & \multicolumn{4}{|c|}{$0-9.9$ years } & \multicolumn{4}{|c|}{$10-19.9$ years } \\
\hline & $\begin{array}{l}\text { Boys } \\
\text { No }\end{array}$ & Rate* & $\begin{array}{l}\text { Girls } \\
\text { No }\end{array}$ & Rate* & $\begin{array}{l}\text { Boys } \\
\text { No }\end{array}$ & Rate* & $\begin{array}{l}\text { Girls } \\
\text { No }\end{array}$ & Rate* \\
\hline 1971 & 203 & 1.8 & 108 & 0.9 & 539 & 5.6 & 452 & $4 \cdot 7$ \\
\hline 1972 & 208 & 1.9 & 126 & $1 \cdot 2$ & 451 & $4 \cdot 6$ & 391 & $4 \cdot 0$ \\
\hline 1973 & 205 & $2 \cdot 0$ & 130 & $1 \cdot 3$ & 482 & 5.0 & 452 & $4 \cdot 7$ \\
\hline 1974 & 212 & $2 \cdot 1$ & 142 & 1.4 & 523 & 5.4 & 461 & 4.8 \\
\hline 1975 & 193 & $2 \cdot 0$ & 114 & $1 \cdot 2$ & 478 & 4.9 & 400 & $4 \cdot 2$ \\
\hline 1976 & 166 & 1.8 & 188 & $2 \cdot 1$ & 473 & 4.9 & 400 & $4 \cdot 2$ \\
\hline 1977 & 155 & 1.8 & 96 & $1 \cdot 1$ & 490 & $5 \cdot 1$ & 446 & $4 \cdot 7$ \\
\hline 1978 & 116 & 1.4 & 77 & 1.0 & 375 & 3.9 & 320 & $3 \cdot 3$ \\
\hline 1979 & 103 & 1.4 & 70 & 0.9 & 476 & 5.0 & 310 & $3 \cdot 2$ \\
\hline 1980 & 79 & $1 \cdot 1$ & 64 & 0.9 & 427 & $4 \cdot 5$ & 402 & $4 \cdot 1$ \\
\hline 1981 & 94 & 1.4 & 50 & 0.7 & 414 & $4 \cdot 4$ & 316 & $3 \cdot 3$ \\
\hline 1982 & 86 & 1.4 & 51 & 0.9 & 282 & $3 \cdot 2$ & 221 & $2 \cdot 7$ \\
\hline 1983 & 65 & $1 \cdot 1$ & 54 & 1.0 & 309 & 3.7 & 251 & $3 \cdot 2$ \\
\hline 1984 & 87 & $1 \cdot 5$ & 59 & 1.0 & 296 & $3 \cdot 7$ & 213 & $2 \cdot 8$ \\
\hline 1985 & 57 & 1.0 & 37 & 0.7 & 240 & $3 \cdot 2$ & 179 & $2 \cdot 5$ \\
\hline $1971-78$ & 1458 & 1.9 & 981 & $1 \cdot 3$ & 3811 & $4 \cdot 9$ & 3322 & $4 \cdot 3$ \\
\hline $1979-85$ & 571 & $1 \cdot 3$ & 385 & 0.9 & 2444 & $4 \cdot 0$ & 1892 & $3 \cdot 1$ \\
\hline
\end{tabular}

*Annual discharge rate per 1000 children in GGHB catchment area.

Table 3 Underlying trends in annual hospital discharge rates for acute appendicitis with appendicectomy in Glasgow Asian and white children between 1971 and 1985

\begin{tabular}{llllll}
\hline & \multicolumn{2}{l}{ Boys } & & \multicolumn{3}{l}{ Girls } \\
\cline { 2 - 3 } \cline { 5 - 6 } \cline { 5 - 6 } Group & $\begin{array}{l}\text { Regression } \\
\text { coefficient }\end{array}$ & $p$ value & $\begin{array}{l}\text { Regression } \\
\text { coefficient }\end{array}$ & $p$ value \\
\hline Asian (0-9.9 years) & -0.02 & 0.7 & & -0.04 & 0.4 \\
White (0-9.9 years) & -0.07 & 0.001 & -0.04 & 0.05 \\
Asian (10-19.9 years) & +0.35 & 0.02 & +0.02 & 0.8 \\
White (10-19.9 years) & -0.14 & 0.001 & -0.15 & 0.001 \\
\hline
\end{tabular}

in trends in discharge rates between Asian boys and girls aged 10-19.9 years but not between boys and girls aged $0-9.9$ years (table 4 ).

\section{Discussion}

Between 1971 and 1985, annual discharge rates for appendicectomy for acute appendicitis fell in Glasgow white children in keeping with national trends. ${ }^{6}$ While discharge rates for younger Asian children were stationary over this period, those for older children rose; the greatest rise occurred in adolescent Asian boys. These divergent trends are consistent with the hypothesis that older Asian children are adopting more western dietary patterns. If true, this should be most evident in older Asian boys.

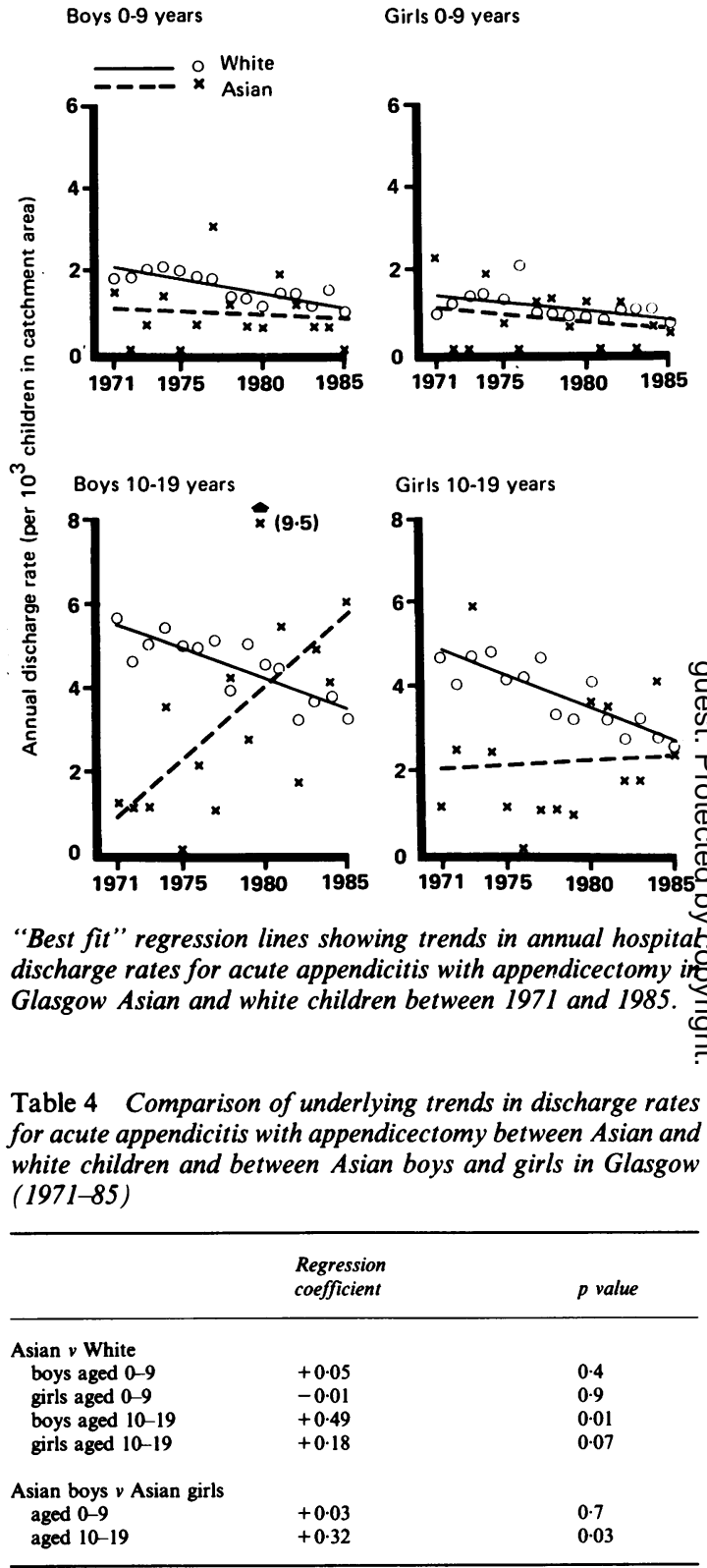

Before puberty, Asian boys and girls eat together and their meal patterns are similar. After puberty, boys and girls usually eat separately, girls with their mother and older female members of the family, boys with their father and older brothers. Personal experience of Glasgow Asian children by two of the authors (JBH and MGD) suggests that older Asian boys have more freedom to eat western foods both in 
and out of the home. Girls remain more conservative in dietary habit, conforming more closely in this and other ways to traditional Asian cultural patterns.

Barker ${ }^{6}$ has shown that changes in the consumption of fibre, meat and sugar cannot explain time trends in the incidence of appendicitis in Britain between 1895 and 1980 . He speculated that the rise in incidence between 1895 and the 1930s and the subsequent gradual decline might be due to changes in population immunity to respiratory and enteric infections resulting from improved living standards and sanitation. The results of the present study are difficult to reconcile with an infectious aetiology. The Asian adolescents who showed a rising incidence of appendicitis were almost all born and brought up in Glasgow and shared the same microbiological environment as the indigenous population. More specifically, an infectious aetiology is unlikely to account for the significantly more rapid rise in incidence in older boys compared with girls. The evidence of the present study is more consistent with the hypothesis that the observed age- and sex-related changes in appendicitis incidence reflect differing rates of adaptation to a western diet from a traditional lactovegetarian one. Barker's ${ }^{6}$ suggestion that dietary change may mediate changes in appendicular flora provides a possible mechanism linking the effects of relatively rapid dietary change with an infectious aetiology which may determine longer-term trends in incidence.

The present study has shown that the impact of environmental change on disease incidence in small ethnic minority communities is measurable provided the size of the population denominator can be estimated with reasonable confidence. A case-control study of the diets of Asian children who have had appendicectomies would be of value in establishing more precisely the degree of adaptation associated with this common illness of western countries.

We are most grateful to Mrs Razia Meer who identified Asian children disharged from hospital with acute appendicitis by name.

Correspondence to $\mathrm{Dr}$ M G Dunnigan, Stobhill General Hospital, Glasgow G21 3UW.

\section{References}

I Rendle Short A. The causation of appendicitis. Br J Surg 1920; 8: 171-88.

2 Burkitt DP. The aetiology of appendicitis. Br J Surg 1971; 58: 695-9.

${ }^{3}$ Donaldson LJ, Taylor JB. Patterns of Asian and non-Asian morbidity in hospitals. $\mathrm{Br} \mathrm{Med} J \mathrm{1983}$; 286: 949-51.

${ }^{4}$ General Register Office, Edinburgh, Census 1971, Scotland. Usual incidence and birth place tables. Edinburgh: HMSO, 1974.

${ }^{5}$ Registrar General, Scotland. Census 1981, Country of birth. Edinburgh: HMSO, 1983.

${ }^{6}$ Barker DJP. Acute appendicitis and dietary fibre: an alternative hypothesis. $\mathrm{Br} \mathrm{Med} J$ 1985; 290: 1125-7.

Accepted for publication April 1988 